\title{
Inscripciones postsoviéticas en la literatura cubana actual. Futuros negativos y desfiguraciones de lo humano en El imperio Oblómov de Carlos A. Aguilera
} Post-Soviet Inscriptions in Cuban Literature. Negative Futures and Disfigurement of the Human in El imperio Oblómov, by Carlos A. Aguilera

\author{
Irina Garbatzky \\ Universidad Nacional de Rosario \\ irinagarbatzky@conicet.gov.ar
}

\begin{abstract}
En una gran parte de la literatura cubana escrita por la generación de autores que comenzó a publicar alrededor de 1989 y hasta la actualidad puede leerse la insistencia de varios significantes vinculados con imaginarios soviéticos: rusos, de Europa oriental, chinos. Rafael Rojas (2009) ha señalado los vestigios exotistas que parece haber en dicho ejercicio, mientras que otros críticos, como Jacqueline Loss o Damaris Puñales Alpízar (2013), entienden el retorno como una pulsión identitaria en la diáspora, una comunidad de sentimiento soviético cubana. En el siguiente artículo nos interesa abordar la hipótesis de que una de las claves para leer la inscripción del archivo soviético se relaciona con la dislocación y la desfiguración de dos nociones fundamentales del imaginario de la Revolución. Por un lado, un profundo cuestionamiento del pensamiento moderno de la futuridad vanguardista y, por otro, la exploración de los procesos de refundación y desmoronamiento del ideal del "hombre nuevo", lo que supone nuevas formulaciones del cuerpo y de sus constelaciones biopolíticas. Con el fin de argumentar estas cuestiones analizaremos la obra literaria del cubano Carlos Aguilera, tomando como punto de partida la novela El imperio Oblómov (2014).
\end{abstract}

Palabras clave: Cuba postsoviética, literatura cubana actual, Carlos Aguilera, comunismo, revista Diáspora(s).

In much of Cuban literature written by the generation of authors who began publishing around 1989 and until today it can be read at the insistence of a number of significant linked with Soviet imaginary: Russian, Eastern European, Chinese. Rafael Rojas (2009) has identified the exotic remains seems to have in that practices, while other critics, as Jacqueline Loss or Damaris Puñales Alpizar (2013) understand the return as an identity in the Diaspora, a community of Cuban Soviet sentiment. In the following article, we want to address the hypothesis that one of the keys to read the inscription of the Soviet file is related to the dislocation and distortion of two fundamental notions of the imaginary of the Revolution. On the one hand, a profound questioning of modern thought edgy futurity, and secondly, exploring the processes of refounding and collapse of the ideal of the "new man", which involves new formulations of the body and its bio-political constellations. To argue these issues analyze the literary work of the Cuban Carlos Aguilera Chang, taking as a starting point the novel El imperio Oblómov (2014).

Keywords: Post-soviet Cuba, cuban literature, communism, revista Diáspora(s), Carlos Aguilera. 
En una crónica del diario La discusión, en 1890, Julián del Casal describía, casi como una anticipación, el encuentro entre el trópico y la Siberia. En ella, un sacerdote ruso en una fragata rusa, que zarpaba desde el puerto de La Habana, observaba el mar con fijeza. "Diríase", imaginaba el modernista al mirar al sacerdote, "que trata de concentrar en sus pupilas verdes, inmóviles en sus órbitas aporcelanadas, los brillantes fulgores del mediodía tropical, para iluminar con ellos, en futuros días, la blancura helada de las vastas estepas solitarias" (2012: 96). A pesar del recorte exótico del hombre -es como un personaje de Dostoievsky, sostiene-, lo que se oye es lo propio, que el viaje se lleva, la isla proyectada sobre la Siberia. Acerca del traslado y la cercanía de esas dos geografías tan disímiles, se sobreimprime el tiempo; el ruso habrá de recordar, en el brillo helado de la nieve, el calor metalizado del mar.

Si se sigue la imagen, podríamos preguntarnos qué recuerdo para el futuro estarían formulando ahora aquellos autores cubanos cuyos títulos configuran, al ponerlos en línea, el armado de una serie. Pensemos, por ejemplo: Enciclopedia de una vida en Rusia, Livadia, Siberiana, Corazón de Skitalietz, Cartas desde Rusia, Das Kapital, El Imperio Oblómov, Cuadernos de Feldfalding, Asia Menor, "Mao", Teoría del alma china. Todos títulos de libros, de cuentos o poemas escritos entre los años noventa y comienzos del 2000, por ciertos autores, diversos entre sí (José Manuel Prieto, Jesús Díaz, Antonio José Ponte, Emilio García Montiel, Carlos Aguilera, Rolando Sánchez Mejías), cuya marca generacional está dada por haber comenzado a escribir y publicar en La Habana durante el "Período especial", con 1989 y la caída de la URSS como horizonte.

¿A qué se debe la insistencia de estos imaginarios soviéticos y eurasiáticos en la literatura cubana actual? En Escrito en cirílico. El ideal soviético en la cultura cubana posnoventa (2013), Damaris Puñales Alpízar pensó en una comunidad imaginada, aunada por la vivencia en común de haber crecido y haberse formado durante la sovietización cultural, tanto a partir de los dibujos animados rusos hasta los viajes a Rusia como formación técnica. La lectura de Jacqueline Loss (2003 y 2009), por su parte, trama la ambivalencia que lo ruso y soviético soporta en la memoria; sus efectos, si bien negados por algunas voces de la política cultural de la isla, retornaron en la producción de artistas y escritores como pregunta afectiva respecto de la infancia, o bien nostálgica, en un período de escasez, de una época de mayor bienestar económico1. Por otro lado, Rafael Rojas (2009) metaforiza la relación metropolitana entre La Habana y Moscú con la figura del souvenir; la escasez de rastros edilicios de la URSS contrasta con la importante presencia soviética en

1 Esta "ostalgia" y esta tensión entre lo rechazado y lo querido también es leída por Duanel Díaz (2007) cuando analiza las recuperaciones, en blogs, de los dibujitos animados soviéticos, con los que creció su generación. Díaz encuentra que, a diferencia de la idea de "ostalgia" observada por Slavoj Zizek, la recuperación y circulación de los dibujitos rusos, especialmente entre los cubanos en el exilio, se vincula antes con una cuestión identitaria que por un apego al socialismo real. En este sentido, para Díaz lo ostálgico en Cuba vendría a reforzar y enfatizar el trauma que significó la caída de la URSS. No se trataría de la conciencia de la pérdida de un mundo singular, precioso, y seguro, frente al mundo dinámico e individualista del capitalismo, sino de un pasaje que señaló, desde las carencias, la relativa abundancia de los años ochenta. 
los programas de educación, traducciones y revistas que circularon durante la década del setenta. Aquí la figura se encuentra menos ligada al vestigio que a la joya, el souvenir como fetiche liga un más acá con un más allá, y en este sentido, también remite a la relación exótica entre la isla y la nieve.

Podría decirse que la experiencia de la sovietización cultural retorna bajo la forma de un tiempo desprendido y divergente de la temporalidad progresiva con la que Occidente definió la modernidad, de la idea de sobrevivencia de los proyectos utópicos del pasado como futuros potenciales, dispuestos para un ejercicio que permita transformar el presente. A su vez, los retornos de lo soviético apuntan a problematizar el estatuto humanista, central en la conceptualización del "hombre nuevo" de la Revolución -cuyas delimitaciones podían leerse en "El socialismo y el hombre en Cuba", el ensayo que Ernesto Guevara envió a la redacción del semanario Marcha, en 1965-, a partir de la puesta en juego de varios discursos que fugan y resquebrajan los modelos clásicos de biopoder, al tiempo que deforman el ideal de corporalidad moderna y lo acercan a otros modelos de lo viviente: monstruosidades, aberraciones, experimentos genéticos o animales.

Para observar estas hipótesis proponemos una lectura de la novela de Carlos Aguilera, El imperio Oblómov (2014), en el marco de su trayectoria literaria, muy especialmente atravesada por las búsquedas experimentales del grupo y la revista Diáspora(s), que tuvieron lugar durante la década del 90 en La Habana.

\section{Un espacio contrautópico}

La dinámica de los restos de lo soviético en la literatura cubana actual requiere de una reflexión pertinente a matices divergentes respecto de los modos de relatar la temporalidad de las vanguardias en Occidente. Si un modelo ejemplar y sumamente eficaz para la lectura de las persistencias y renovaciones de los impulsos vanguardistas en el Cono Sur fue el artículo de Hal Foster "What's neo about the neo-avant-garde?", de 1994, el archivo revolucionario descubre aristas de la temporalidad que plantean algunas distancias con el esquema que allí se presenta.

Para Foster las neovanguardias elaboraron comprensivamente el efecto traumático de su significación en el comienzo de siglo XX, de tal forma que sus restos no cesarían de regresar desde un futuro que siempre comprende retrospectivamente la experiencia y, por tanto, la recodifica. En los países del bloque comunista este esquema presenta algunos puntos de intensísima paradoja temporal. Susan Buck Morss y Boris Groys lo señalan, al observar la temporalidad singular que supuso la revolución socialista. En Mundo soñado y catástrofe (2004) y Obra de arte total Stalin (2008), respectivamente, ambos plantean la suspensión del tiempo de la vanguardia cultural en el caso soviético. No habría habido una utopía sin efecto que sepultara los anhelos de revuelta, sino, por el contrario, una efectuación total del programa vanguardista, en la instauración de un nuevo presente. Según Groys, a pesar de las persecuciones y de los rechazos de la vanguardia, el estalinismo significó una ejecución a escala máxima de los proyectos artístico-políticos de la vanguardia. La época de Stalin hizo realidad la exigencia fundamental de la 
vanguardia de que el arte pasara de la representación de la vida a la transformación de esta con los métodos del proyecto estético político total, dando por finalizada cualquier idea de utopismo, construyendo un más allá de los límites de la historia, "un futuro apocalíptico absoluto en el que la distinción entre futuro y pasado pierde su sentido" (144). Por su parte, algunos años antes Susan Buck-Morss realizó una lectura de la cultura soviética tomando como punto de partida los orígenes del comunismo y del capitalismo como dos instancias inscritas en los sustratos de la modernidad, de la cultura de masas y de sus sueños colectivos. Esta posición le permitió entender de qué modo la revolución bolchevique se había planteado como una instancia superadora de Occidente, "fomentando la tradición revolucionaria mundial hasta su más alta culminación", una idea tan deudora de Hegel como la idea de progreso moderna. A pesar de que la vanguardia cultural (avant-garde) y la vanguardia política (vangard) poseían dos temporalidades distintas (la temporalidad de la ruptura versus la inserción en una cosmología histórica), la primera cedió a la segunda.

Más allá de las indiscutibles distancias, históricas, culturales y políticas, entre la Unión Soviética y Cuba, esta diferencia, entre la concepción de un presente que busca transformarse hacia un futuro que siempre está por venir y la de un presente que se encuentra con el día después de un futuro ya cumplido, se ha vuelto crucial para pensar la literatura cubana del "Período especial". En los ensayos de los escritores cubanos que pensaron su propia generación vuelve la reflexión acerca de la singular condición y percepción de la temporalidad del comunismo. Iván de la Nuez, por ejemplo, en la antología hecha en el 2001, Cuba y el día después, para pensar la literatura cubana contemporánea enfatiza el dato del nacimiento de algunos autores, poco más acá y más allá de 1959. Son "los hijos de la revolución", aquellos niños nacidos y criados durante el comunismo, los que fueron literalmente los hombres nuevos para Cuba y para el mundo. Son los miembros de una generación que creció con la conciencia de encontrarse habitando el futuro del mundo y de que su producción proviene de aquella futuridad:

Si algo saben estos escritores es que no basta con pensar el futuro. Es necesario situarse en él. Y esto a pesar de que se enfrenten, en un acto de esta envergadura, a una paradoja fundamental: el Futuro, así con mayúscula, ya ha sido habitado por ellos. ¿No nacieron y crecieron escuchando que "el futuro pertenece por entero al socialismo"? ¿No fueron ellos los elegidos incontaminados, hombres y mujeres que crecerían sin la sombra del capitalismo hasta un mundo sin dinero y sin clases? Ahora, recién despertados del sueño futurista, recién llegados de ese porvenir, se ven conminados a imaginar y vivir un mundo diferente al prometido. Como si se balancearan en una cuerda floja entre el futuro perdido y el futuro posible (2001, 9-10).

De esta manera, la dislocación temporal tensiona la escritura de estos autores, formula un punto de detención. Se trata del problema de los hijos, aquellos que, como decía Goethe, para poder recibir su herencia deben 
apropiársela, y sobre todo se trata del problema de los hijos de la revolución, es decir, de aquellos niños que crecieron al calor de una paradoja crucial entre dos tiempos colisionados: el efecto de fin del mundo (el futuro ya llegó) y la utopía como origen perdido (el futuro ya se fue).

En El imperio Oblómov (2014) de Carlos Aguilera el futuro que se presenta también forma parte de un tiempo desarticulado. La novela transcurre en el siglo XIX, en "La Gran Eslavia", una zona que va desde las fronteras de Austria hasta el Báltico, pasando por Polonia y el norte germánico, territorio que se identifica, simplemente, como "el Este". En el título, Aguilera retoma, además, el nombre de otra novela decimonónica: Oblómov, de Iván Goncharov, publicada en 1859, relato que caracterizaba la decadencia zarista. La novela de Aguilera se ocupa de la invención de una familia monárquica ficticia, los Oblómov, enfrentada con exiliados rusos y también con anarquistas. Aunque transcurra en el siglo XIX, la ficción se encuentra intervenida por varios anacronismos, leídos en la intromisión de algunos nombres, como Kropotkin, Binswanger, o Koch, o incluso en ciertos datos referidos a los años 90. Según Pedro Marqués de Armas (2015), esta Gran Eslavia que transgrede los tiempos y la verdad, "supone, más que nada, una síntesis: el diagrama de otros tantos mapas y configuraciones, lo que resulta válido, también, para esa genealogía 'montada' en los Oblómov".

La novela, así, se estructura como las muñecas rusas o las cajas chinas: imagina una nación y una familia, que a su vez, imagina una nación y una familia. Si bien se trata de un tópico de la literatura eslava (y especialmente soviética), el pensamiento de una nación que subsuma las diferentes etnias nacionales, también se trata de un tópico de la literatura latinoamericana, que especialmente trae a la memoria la novelística del boom de los sesenta, invirtiendo, o dislocando, justamente, el punto de vista cartográfico. En la parte final del libro, de hecho, se adjunta una "Genealogía del Imperio Oblómov", que recuerda muy socarronamente a Cien años de soledad, particularmente el énfasis sobre la endogamia y el incesto, mediante las reiteraciones de los nombres a lo largo de las generaciones -El Gran Oblómov, en nupcias con Oblómovina engendraron a Mamushka Oblómov, quien se casa con Oblómov el Grande, para tener por hijo a Oblómov el Tuerto.

El tema es entonces la diagramación de ese mapa y la construcción de esa tierra, el Imperio. La primera cuestión se asocia al pensamiento insular y a cómo circundar un espacio utópico; una circunscripción que se cifra en la torre que el protagonista debe construir. Como se recordará, en La fiesta vigilada (2007) de Antonio José Ponte -uno de los libros que mejor describía las transformaciones vividas en Cuba durante los años noventa-, al momento de pensar su regreso a La Habana después del exilio el autor también recuperaba la imagen de la torre; a partir de la historia de Guy de Mauppasant y de su delirio paranoico (que iba en concordancia, además, con el clima enrarecido de vigilancia y espionaje que el libro se dedicaba a revisar). Según Ponte, horrorizado por el "engendro" que consideraba a la torre Eiffel, Maupassant pasaba horas arriba de ella, ya que ese sería el único lugar desde donde no podía verla. "Igual al Maupassant de esa anécdota", decía Ponte, "mi permanencia en Cuba estaba dictada por el deseo de olvidar. Dentro de Cuba, no veía a Cuba" (17). 
Así como para Ponte (y también para Casal) ${ }^{2}$ el refugio en lo alto de una torre definía el sitio no solo de autoaislamiento sino a la vez de individuación contrahegemónica, la torre regresa, en la novela de Aguilera, como proyecto capital de Oblómov el Tuerto, el heredero de la dinastía. Allí también se imagina un Imperio en un sitio cercado y delimitado, pero en este caso lo utópico se sostiene (y subvierte) en el hecho de que debe resguardar los engendros, la monstruosidad y la rareza del mundo. El espacio contrautópico que se propone es aquel territorio donde se pueda "fundar una humanidad que pudiera salvarse a partir de sus defectos: el cáncer, la idiotez, el no-ojo, el tumor, la hepatitis" (127):

Un imperio donde el defecto e incluso lo muerto fuesen en sí una construcción de vida. Un imperio donde el dolor no fuese más una experiencia desagradable, reumática, sanguinolenta, con garras y pezuñas encarnadas, que hubiese que esconder por debilidad o conflictos estéticos en alguna parte. (...) Un imperio donde la entrada estaría regulada ante todo por la experiencia de la pérdida (...) Un imperio donde muchos estarían contentos de poder presentarse sin miedo ante el otro, aunque fuesen gordos o tuviesen una llaga supurante en el rostro. Aunque les faltase un pedazo de cráneo, nariz, hígado o cuello (128).

La torre, como espacio cerrado sobre sí, traza entonces la figura de la isla. Lo insular regresa como figura de un territorio propio, y este movimiento recorre la literatura caribeña como forma de articular la identidad en la escritura. Según Mónica Bernabé (2012), las incesantes figuras de la isla en la literatura del Caribe implican un sitio discursivo que se encarna en los cuerpos de sus hablantes. En este caso, el motivo de la torre retoma el problema de lo nacional, solo que en lugar de provocar la reminiscencia de una identidad, el recuerdo de una pertenencia, aquí lo utópico apunta a su descomposición. La tierra prometida, lejos de suponer una totalidad, se destina a los infinitos modos de individuación de lo viviente. Un imperio antiimperial, una nación de lo no atrapable: "un lugar de donde no habría que huir, ya que estaría compuesto de la experiencia de fuga de cada uno de nosotros" (14). En la imprecisión que sugiere como zona aquella "Gran Eslavia" y en el marco de un tiempo semianacrónico (las reminiscencias de los siglos zaristas), el Imperio concuerda con el modelo distópico e ingrávido, desprendido de su presente y de cualquier modelo temporalizador, que Odette Casamayor-Cisneros (2012) identificó como modos de restitución de nuevas cosmologías en la literatura cubana postsoviética.

La torre de la aberrante dinastía Oblómov cita y desmonta el imaginario de Latinoamérica como reservorio de una nueva humanidad y como locus de lo utópico, una historia que llegaría hasta las figuraciones maravillosas

\footnotetext{
2 Julián del Casal vivió en un cuarto de la redacción del periódico El país, rodeado de reproducciones de Gustave Moreau y objetos con motivos orientales. El retiro, entonces, apuntaba a la individuación al tiempo que a la asimilación de la estética decadente europea en pleno trópico.
} 
de la escritura de Colón, con sus imágenes de la abundancia y del "buen salvaje", pero que en el caso cubano remite directamente a las metáforas de renovación del hombre y del mundo proyectadas por la revolución, no solo como espacio alternativo al binarismo de la guerra fría, sino sobre todo -seguimos aquí a Claudia Gilman (2003) y su excelente historización de la isla como faro para el campo intelectual latinoamericano del período- como verdadero centro irradiador de la transformación mundial de la política, la vida y la intelectualidad, desde el Tercer mundo.

La topología de lo utópico, además, implica una trascendencia; para llegar a ella es necesario un acto heroico, un enorme esfuerzo y una lucha. Según Juan Carlos Quintero Herencia lo revolucionario se espacializó como un "más allá" en Cuba, encontrando que el futuro definía a la nación y la verdad a partir de la experiencia de una lejanía: "La voz del Líder es un más allá, Cuba está más allá, el sentido de lo revolucionario es un más allá que requiere un difícil viaje" (16). En este sentido, lo utópico como espacio-tiempo por venir no se separa de la pronunciación de una distancia, siempre surcada de obstáculos, que la Revolución debía enfrentar. La futuridad, según Jorge Monteleone (1989) en su análisis de las vanguardias literarias hispanoamericanas, resulta tanto una categoría temporal como espacial, pero para poder tener eficacia precisa de la postulación de un mito de origen, la fabricación de una génesis. Indisolublemente ligada a las vanguardias artístico-políticas de comienzos de siglo XX, la idea de revolución aúna, de este modo, lo radicalmente nuevo con lo constructivo, y la época abierta durante la revolución cubana, además, se caracteriza por la percepción de la inminencia de dicha transformación total.

El futuro como punto neurálgico para la articulación del discurso revolucionario se escenifica en primer plano, entonces, para su posterior desarticulación. Al fin de cuentas la novela insiste en relatar el mandato que recibe el heredero del Gran Oblómov para la edificación de un Imperio y su adhesión a la "Causa paneslavista" (114) y la permanente fantasía y planificación del hijo respecto de cómo será ese país. Visiones proféticas que el príncipe recibe del futuro, como mandamiento demoledor del padre:

¿Acaso no podemos imaginar que después de haber visto su futuro (la violencia siempre genera futuro), Oblómov el Tuerto se había quedado totalmente inmóvil, frío, encima de su cama, en lo que la imagen del padre se desprendía como una estatua de plomo desde lo alto de un muro hasta el piso fraccionándose en veinticinco pedacitos? (126).

Sin embargo, a pesar de hallarse encomendado a la construcción de una torre, los sentidos de futuro para Oblómov se despojan de valoraciones positivas o promisorias. Por el contrario, sus orientaciones se alejan rotundamente de cualquier ideal edificante o estimulante. Son futuros desmentidos, desechados antes de llevarse a cabo: "Si dijera, el Este es el lugar adecuado para mí, el espacio donde alguna vez sentí que lo futuro tomaría forma, mentiría". Son futuros que se construyen como amenaza: "'O aplauden o les rompo el futuro'" (215). Son también futuros que pronostican una condena 
vigilada: "lo vi [al Gran Oblómov] con su pijama de cuadritos ponerle la mano encima a alguien y decirle con vocecita ronca, no te preocupes, ese ya es hombre muerto" (17).

Además, si la futuridad revolucionaria se ligaba a un nuevo espacio y a la formulación de una nueva humanidad, el Imperio de los Oblómov postula una genealogía degenerativa. Puesto en primer plano el vínculo raza-territorio, desde el inicio de la novela ("Un hombre que piensa en la alianza entre raza y locus es, sin dudas, una psicología especial. Un hombre que ha sido dotado para mostrarle al otro el lugar donde se puede construir algo" (10)), resulta claro, en su lectura posterior, que lo que resta de esa alianza resulta un vuelco, un quiebre, una disonancia con la articulación modelada en la metáfora de Calibán como el esclavo mestizo y rebelde, como bien lo desarrollara Roberto Fernández Retamar en 1971, recorriendo no solo especialmente la literatura caribeña sino la de Latinoamérica en general, con el fin de ver las identificaciones con el pasado indígena y el rechazo del colonizador en los intelectuales latinoamericanos, y poniendo en primer plano a José Martí ("Martí ha escrito que sentía correr en sus venas sangre de caribe, sangre de Calibán", 2004: 41). En la serie de Oblómov, el vínculo entre el espacio y la raza no es híbrido sino endogámico; y sus vástagos no son esclavos que luchan contra sus padres colonizadores, sino los ejemplares deformes de una familia monárquica.

\section{La nueva estirpe}

Así como el futuro no presentaba la promesa de una construcción vital, tampoco la estirpe del Imperio supondrá el establecimiento de una nueva humanidad. Si la tierra prometida para la familia Oblómov se presentaba como contrautópica, con un futuro amenazante y violento, también la humanidad y corporalidad que allí se muestra resulta una abyección. El largo retrato del protagonista compone la figura del príncipe, y la descompone, en un procedimiento que lleva barrocamente a su destitución:

Oblómov ojo único, Oblómov Satanás, Oblómov cara de buey, Oblómov oyente de la Zolová y por lo mismo defenestrador de la Zolová, Oblómov parricida, Oblómov asesino de zorros, Oblómov sin expresión en el rostro, con un escapulario de madera en la mano y un paisaje con arbolitos detrás, Oblómov tirano, [...] Oblómov coleccionista, hematoso, con largos monólogos sobre sí mismo y una mirada desconsolada, a punto de infarto, Oblómov con peluca, con una cuchillita en una mano y su retrato -su propio retrato- en la otra, aleccionando sobre la verdadera mística, la de la taxidermia y extinción de los pájaros: esos que han nacido para cagarlo todo, Oblómov contra el virus, lo inmóvil, lo muerto, en una caja blanca con una estaca clavada encima del ombligo y la imagen casi distraída de un Voivoda detrás, Oblómov con dos huesitos, tres huesitos, cuatro huesitos, enterrando a uno de sus demonios bajo una montaña de fango en la fosa de un cementerio (124-125). 
Llegamos al segundo punto que nos interesa: la serie abierta alrededor del desborde de una dimensión corporal moderna, entendiendo por esta aquella que se hallaba destinada exclusivamente a la productividad o la guerra ${ }^{3}$. Los caminos por los que se desbordan dichos funcionamientos contrastan, exacerbándose paródicamente, con la expansión que cobra en la novela el imaginario del higienismo cientificista y los métodos lombrosianos de estudio criminalístico; algo que se observa por ejemplo en los capítulos que describen los estudios de los rostros y facciones de los anarquistas y las teorías escritas por los doctores acerca de "prácticas de desestabilización en el mundo contemporáneo" (67) o de Bertholdo, el doctor que atiende a Mamushka Oblómov mientras dedica su tiempo a vigilar con prismáticos a sus pacientes del hospital psiquiátrico de Schloss Sonnestein. Cada secuencia biologicista se acompaña de su oposición decadente: Bertholdo muere en un acto sexual con su muñeca Bertholda; Oblómov el Tuerto avista el destino del Imperio en la violación de una oveja llamada Marija, por tres campesinos rusos.

Las menciones del control de un poder central apuntan a un entorno que se remonta a las instituciones propias de las disciplinas clásicas del biopoder; en este caso, la escuela, el manicomio, el hospital. Cada elemento parece proponer un gesto cómplice con Michel Foucault en este sentido, sobre todo por la insistencia en la mirada panóptica, que se encarna y se focaliza en primerísimo plano en el ojo izquierdo, hueco, rezumante y podrido de Oblómov el Tuerto, el heredero de la familia, que nunca cesa de observar absolutamente todo lo que sucede en el Imperio.

No obstante, si bien la mirada se vuelca como función disciplinadora, al mismo tiempo resulta el pivot de un funcionamiento delirante, que por lo general termina por conducirla, arrastrando a los personajes al límite de lo humano, lo animal o lo patológico. Aquí también puede pensarse en Foucault -en su apartado final del primer tomo de la Historia de la sexualidad (1977), o bien en las clases de su curso en el Collège de France Defender la sociedad, dictado en 1976-; me refiero al pasaje de las sociedades disciplinarias a las sociedades de control, de las tecnologías de captación sobre el cuerpo individual a las gestiones sobre la población y la administración de la vida, de los problemas del cuerpo como máquina a los problemas del cuerpo como especie: "transido por la mecánica de lo viviente" (Foucault 2002: 168); en síntesis, del derecho de "hacer morir" o "dejar vivir" al de "hacer vivir" o "dejar morir", un traspaso clave para la comprensión del nacimiento de la biopolítica. La distinción de esos elementos resulta fundamental para entender la articulación entre las políticas del cuerpo y las tecnologías respecto de la vida en Cuba, en ese momento crítico que supuso el "Período especial" y la caída de la URSS. Ya que para los escritores que publican por esos años, se les vuelve preciso agregar, junto a los modos de fuga y de descripción de un poder omnímodo, las formaciones productivas, positivas y proliferantes del poder sobre lo vivo,

3 David Le Breton (2002) analiza los modos en los que se interpretó y codificó el cuerpo en la modernidad a partir de estos dos grandes intereses. 
su capacidad de metamorfosearse y sostener distintas formaciones de lo orgánico, los modos de "un poder destinado a producir fuerzas, a hacerlas crecer y ordenarlas más que a obstaculizarlas, doblegarlas o destruirlas" (Foucault 2002: 165).

Entre el poder sobre los cuerpos de los individuos (forma de poder sustractiva y disciplinar), y el poder sobre la vida (forma de poder productiva y proliferante), se escribe toda la novela de Aguilera. Acaso sea pertinente colocar como ejemplo de dicho pasaje y articulación de un elemento con otro, un breve párrafo, en el que se describe la maestra de escuela:

Antes de subir al estrado donde debía enseñarnos a pronunciar adecuadamente algunas palabras o cantar el himno de la región, [la maestra de escuela] se lo desabrochaba lentamente, nos miraba, estiraba los puños de su camisa acartonadamente blanca, nos miraba, extendía su mano para que algunos de los alumnos de primera fila le sirvieran de apoyo, nos miraba, alzaba la nariz y contenía la respiración, nos miraba, y emitiendo un gritico histérico saltaba al estrado, intentando remar al unísono con sus dos grandes aletas y sus dos piernas gigantes de marmota sobre el aire (el destacado es mío, 12).

Aquí se observan con claridad los dos anclajes señalados por Foucault en relación con la fuerza del poder sobre los cuerpos y su transmutación: de la mirada panóptica a una conversión animal; lo que también significa un rebajamiento de la mirada como sitio de la razón mediante una metamorfosis: piernas-aletas-patas.

La transmutación hacia lo animal a partir del forjamiento de una nueva especie de lo humano se figura incesantemente a lo largo de El Imperio Oblómov. A lo largo de todo el libro se escenifica la irrupción que arrastra a los personajes a las comparaciones con los animales y otros seres vivos. Las referencias son numerosas. Menciono algunas: la maestra como "cerdito", como "rata" y "marmota" (14), el ser humano como "lobito" (17), los Oblómov como "perros rabiosos" (49), los sueños paranoicos de Oblómov el Tuerto con ratas que lo persiguen (231), la salida de arañas de su cráneo ("arañas, arañitas, arañas gordas, medio arañas... Cada vez que Oblómov el Tuerto se dormía, de su cabeza empezaban a salir arañas. Arañas que copulaban entre ellas haciendo un gran ruido o arañas de patas cortas, prietas, con un poquitico de pelos en los bordes y una cruz en el lomo", 135) y aún mismo su muerte: "Caminó hasta que se quedó dormido y amaneció congelado al lado de un abedul, encima de su escopeta, con varios animales mordisqueándolo y destrozándole la ropa, con la mandíbula suelta, como si sus piernas fueran en sí mismos un par de tronquitos más" (232).

\section{El cuerpo diaspórico de la escritura}

Dicho tránsito, de la violencia y el sometimiento de los cuerpos a las multiplicaciones de formas y perspectivas no humanas, recorre muchos otros 
momentos de la literatura del autor ${ }^{4}$. La perspectiva no humana también se desarrolla en los contenidos que integraron los números del proyecto Diáspora(s), del que Aguilera fue uno de sus gestores, y que se hallaba compuesto además por Rolando Sánchez Mejías, Ricardo Alberto Pérez, Pedro Márquez de Armas, Rogelio Saunders, José Manuel Prieto, Radamés Molina e Ismael González Castañer.

Según los aportes de Duanel Díaz y Jorge Cabezas Miranda publicados en el apéndice crítico de la edición facsímil de la revista (2013), Diáspora(s) funcionó como una vanguardia tardía en Cuba, "avanzadilla (sin)táctica de guerra" que criticaba al "realismo bienpensante" y reclamaba la apertura de espacios de autonomía intelectual durante la crisis de los años noventa. Diáspora(s) tuvo dos períodos, un comienzo como proyecto entre 1993 y 1994, ligado a performances, reuniones, conferencias públicas, grabaciones poéticas radiales; y un segundo momento, en 1997, cuando aparece la publicación. La incorporación de dispositivos de acción artística del proyecto 5 se combinó en ella con la herencia del arte conceptual en el reclamo por una renovación de la crítica y una "poesía del pensar". Ese experimentalismo, que Walfrido Dorta (2013) relaciona con la capacidad de lo ilegible para hacerse escuchar políticamente, se volcó en la teatralidad y la exposición del cuerpo; algo que en la obra de Aguilera se encuentra expandido como una "cuchillita teatral" a lo largo de toda su literatura, provocando procesos de singularización y desidentificación de aquellos esquemas del cuerpo separados binariamente, entre la estética o la política6.

Por tanto, resulta significativo observar las múltiples alusiones que aparecen, desde el primer número, de las referencias soviéticas y asiáticas en la revista. Junto a las traducciones de algunos autores posestructuralistas, hacen su aparición las menciones a la Unión Soviética y China, en las ficciones y poemas de Aguilera, José Manuel Prieto, Sánchez Mejías, y en los ensayos sobre Kundera, de Duanel Díaz, las traducciones de Joseph Brodsky, de los

4 Entre otros muchos ejemplos, pueden mencionarse la relación entre lo animal y lo comunista en la obra de teatro "Discurso de la madre muerta" (2012), donde el monólogo de una madre se conforma en el relato de las acciones de espionaje de un gato ruso, que es a la vez un Estado ( $y$ una de las varias piezas de lectura alegórica allí propuestas, las otras son los gemelos, o la plaga), en "Mao" el poema se centra en la referencia histórica de la gran matanza de gorriones impulsada por el líder chino.

5 Además de la revista, el proyecto Diáspora(s) supuso la exploración por varios dispositivos performáticos, presentaciones radiales y teatrales. Un recorrido de dicha experiencia puede leerse en la entrevista realizada por Idalia Morejón Arnaiz: "Repertorio de poesía y performance. Cuba años noventa". http://www.badebec.org/badebec_7/sitio/pdf/dossier_morejon_7.pdf 6 Dice Aguilera, en una entrevista: Creo que mis textos -igual el género en que finalmente hayan sido escritos- tienen detrás cierta stimmung del teatro, cierto devenir teatral; y por eso son a veces tan exagerados o lúdicos (o exagerados y caricaturescos). No concibo casi nada que no haya pasado previamente por, como decía antes, cierta cuchillita teatral, cierta «disección» que solo te da la escena. Incluso, mis poemas, a veces tan difíciles para algunos, siempre tan abstractos, pasan por esto que vengo diciendo, por ese drama que para mí fluye por debajo de todo". "Nada como el afuera para ver lo enfermito que está el adentro. Entrevistas a Carlos A. Aguilera". La Habana Elegante. Primavera-Verano de 2013. Número 53. http://www.habanaelegante.com/Spring_Summer_2013/Entrevista.html . En El imperio Oblómov, de hecho, el pasaje al texto dramático se observa con toda naturalidad en el paso del diálogo indirecto a la didascalia entre el Gran Oblómov y el Director del hospital. 
"Poemas Cubanos" de Hans Magnus Enzensberger, etc. Junto a esta presencia cultural, se yuxtaponen las recuperaciones del contracanon origenista, desde las inflexiones kafkianas de Virgilio Piñera, las metamorfosis y el juego con el significante de Severo Sarduy o el experimentalismo de Lorenzo García Vega, en el intento de reivindicar poéticas que evadan el lazo indisoluble entre literatura y nación, entre poesía y determinación de una identidad7.

A partir de esta conjunción se despliegan ciertas reflexiones destinadas al vínculo entre los cuerpos y el biopoder. La propuesta diaspórica enunciada desde el título apunta a pensar la escritura en el campo de lo múltiple y lo diverso bajo el signo de una opresión. Así, en el editorial del primer número Rolando Sánchez Mejías habla de la multiplicación de las escrituras, utilizando una cita de Barthes: "la multiplicación de las escrituras es un hecho moderno que obliga al escritor a elegir". E inmediatamente preguntaba: "No sé si Mao pensó, entre tantas de sus multiplicaciones, la multiplicación de la escritura, si puso a los escritores chinos a elegir" e incluso, dice después, se debe "escribir como se cazan gorriones"8.

Lo diverso y exiliado presentan el punto de partida, la ubicación discursiva donde se sitúan estos escritores, que si bien en su mayoría aún viven en La Habana (menos José Manuel Prieto, que se encuentra en México) observan atentamente las vidas de los cubanos en el exilio, preguntándose por el estatuto de la autonomía intelectual y por la posibilidad de su supervivencia en la isla. Según Rojas, de hecho, el factor común que signó el posterior exilio de esta generación de autores no residía en un rechazo unilateral a la revolución, sino en el valor compartido en torno a la diáspora como posicionamiento ético. Más que compartir una posición pública, se trata en "la

7 Para observar este posicionamiento alcanza con leer el índice del primer número: "Che cos'e la poesía?" de Jacques Derrida, "Olvidar Orígenes" de Rolando Sánchez Mejías, "Orígenes y los ochenta", de Pedro Marques de Armas, "Mao", de Carlos Aguilera, "Enciclopedia de una vida en Rusia", de José Manuel Prieto, y "La condición que llamamos exilio", de Joseph Brodsky. Y en el número 2, de enero de 1998: "Ceremonial origenista y teleología insular", de Antonio José Ponte, "En busca de la verdad y de la muerte" y "Viktor Halbnarr/ Un cuento de invierno", de Thomas Bernhard, "Poemas" de Pedro Marqués de Armas, "El fascismo. Apuntes", de Rogelio Saunders, "Señal de Tráfico" de Haroldo de Campos, "Baladas de un Bag Boy", de Lorenzo García Vega, "El gran inquisidor" de Peter Sloterdijk. He consultado los volúmenes de la revista en la edición facsimilar compilada por Julio Miranda (2013).

8 Transcribo el texto completo:

1. La multiplicación de las escrituras es un hecho moderno que obliga al escritor a elegir, que hace de la forma una conducta y provoca una ética de la escritura. Estas palabras de Roland Barthes tal vez sean suficientes para un conato de explicación del proyecto DIÁSPORAS, surgido, como entidad gregaria, en 1993, en La Habana.

2. No sé si Mao pensó, entre tantas de sus multiplicaciones, la multiplicación de la escritura; si puso a los escritores chinos a elegir; a elegir en bien de la nación.

3. De lo que se trata, por sobre todo, es de la obligación. ¿Qué te obliga a escribir en tales circunstancias tal o cual cosa? Debe sentirse alguna presión sobre la nuca.

("Presentación", Revista Diáspora(s) No 1, p. 174 edición facsimilar).

Es importante destacar que hacia el final del número el poema "Mao" de Aguilera reitera esta tensión entre la multiplicación de las escrituras y la violencia del tirano que corta el dedo a sus escribas. La escritura del poema, además, apuesta a multiplicar lo mismo varias veces, del mismo modo que la multiplicación desorbitada y fallida del líder. 
práctica de un conjunto de políticas personales que convergen en el gesto diaspórico de haber abandonado la isla y permanecer fuera de ella" (119) ${ }^{9}$.

Por este motivo, en el número 1 será Joseph Brodsky quien define, casi a la manera de un manifiesto -en el sentido de definición de una imagen, una autofiguración grupal-, la condición exiliada de los escritores modernos. Dice Brodsky en el texto "La condición que llamamos exilio":

El exilio te lleva, en cuestión de días, allá donde normalmente necesitarías una vida para llegar. Si esta frase tiene el tono de un spot publicitario, pues muy bien: tal vez es el momento de lanzar esta idea. Tal vez una metáfora puede servirnos a este propósito: la condición de un escritor en el exilio se asemeja a aquella de un perro o un hombre catapultado al espacio dentro de una cápsula (aunque en este caso se asemeja más a la de un perro, naturalmente, porque ninguno se ocupará nunca de recuperarte). Y tu cápsula es tu lenguaje. Para cerrar la metáfora es conveniente añadir que el pasajero no tarda mucho en descubrir que la cápsula no gravita hacia la tierra, sino más bien hacia lo externo, en el espacio" [...] "Ser dispersados en medio del género humano, de la multitud -¿multitud?-, transformarse en aguja dentro del proverbial pajar -pero una aguja que alguien busca-, eso es, en sustancia, el exilio. Refrena tu vanidad, dice el exilio, no eres más que un grano de arena en el desierto. No te compares con otros hombres de letras, sino con la infinidad humana, que es más o menos tan amarga y triste como la no humana (37 y 34).

A diferencia del modelo "extraterritorial" que proponía George Steiner (1971), pensando en la singular composición lingüística de la literatura contemporánea, aquí el exilio no marca una condición de lengua, ni mucho menos una condición estética; sino que cae, pesadamente, en el cuerpo de quien escribe. Cae sobre lo humano como condición, como naturaleza que lo define o que lo salva. No se trata, entonces, de una experiencia extraterritorial similar a la de escritores como Samuel Beckett o Vladimir Nabokov, para quienes, de alguna manera, la pérdida de su lengua materna podía ser compensada por otra, desplazada y alojada en otra nación. Aquí se trata de resolver el problema de una figura de escritor cuyo exilio forma parte de la disolución de los límites de lo personal; de su contrapunto con aquellas fuerzas que demarcan y delimitan un único modelo de Hombre. ¿Cómo

9 "La generación de los 80 fue la única plenamente producida por el comunismo. Las anteriores llegaron al orden soviético con una juventud, una adolescencia o, al menos, una infancia, vividas en el antiguo régimen republicano. Las posteriores se han formado en el momento poscomunista, es decir, en ese tiempo muerto del período revolucionario que se inicia en 1992 y se extiende hasta nuestros días, como una edad perdida entre el totalitarismo que patalea por subsistir y la democracia que aún no acaba de construirse. Históricamente hablando, se trata, pues, de una subjetividad única e irrepetible, aquella subjetividad que mejor encarna el sueño o la pesadilla del «hombre nuevo»", dice Rojas $(2009,117)$. 
escribe un escritor catapultado al espacio como perro, lanzado fuera del género humano? Tal vez lo haga en un poema como "La nueva estirpe" de Pedro Marques de Armas, también publicado en el número 1 de la revista:

Ya viste los monos en la barcaza

así el delirium de percepción

animales brotan de las celdillas

del cerebro, en ininterrumpida población

y vista alguna roca peduncular

con la vara de cedro ruso que golpea

la puerta: mono, rata, lo mismo hombre/oscuros

tejemanejes del anti-Dios (34).

O posiblemente desarrolle el diario de un escritor-araña, como hace Rolando Sánchez Mejías a lo largo de varias páginas del número 2, en un texto como "Zillia", del que solo transcribiré un pequeño fragmento: "R, miro como tratas de escribir. Te miro a través del ojo de la cerradura. Te montas a la mesa y te mueves a cuatro patas (¿mono?, ¿araña, ¿monoaraña, ¿arañamono?), braceando, pataleando entre las hojas revueltas y en blanco" (22).

De la serie temática que construye la revista puede derivarse una lectura que irá a tensionar la postulación humanista del "hombre nuevo", revelando de qué modo en ella también se presentaba una inquietud biopolítica: la formación de una nueva humanidad, descontaminada de la ideología del capitalismo y de sus formas de la alienación. Para Guevara, en "El socialismo y el hombre en Cuba", el hombre socialista era un hombre futuro, en construcción, un hombre nuevo que debía advenir, junto con las modificaciones de los modos de producción. Se trataba de un proyecto humano ("Para construir el comunismo, simultáneamente con la base material hay que hacer al hombre nuevo"), surgido al cabo de un trabajo sobre las conciencias y los cuerpos que erradicaran los lastres del pasado capitalista. Si previo a la revolución el hombre era "individualizado, específico, con nombre y apellido", luego del levantamiento de Moncada pasaría a ser un individuo parte del "pueblomasa": único y miembro de la comunidad. La masa y la nueva sociedad lo educarían como una "gigantesca escuela", y paulatinamente iría encontrando su plenitud humana, su arraigo social, mediante su relación desalienada con el trabajo, que implicaba, justamente, liberarse de sus necesidades básicas, animales: "El hombre comienza a liberar su pensamiento del hecho enojoso que suponía la necesidad de satisfacer sus necesidades animales mediante el trabajo. Empieza a verse retratado en su obra y a comprender su magnitud humana a través del objeto creado, del trabajo realizado"10.

En Diáspora(s) y en la literatura de Aguilera, las figuras animales que se exponen apuntan a la demolición de ese ideal y al señalamiento de un

10 Laura Maccioni sintetiza las figuraciones del Hombre Nuevo en el Che Guevara como un "sujeto en el que se verifica la unidad estrecha entre conciencia revolucionaria y estructura material" (36). Según la autora, en su confrontación con la dislocación de dicha subjetividad en Reinaldo Arenas, los puntos clave de la subjetividad del Hombre nuevo en el discurso guevarista tenían que ver con el apego a la realidad, el coraje, la virilidad, la acción en combate y la transformación ideológica. 
nuevo cuerpo, lindante con lo no humano o lo posthumano. Entre escenarios, paisajes, traducciones y recuperaciones de voces disonantes respecto del canon nacional, los artículos y textos de Diáspora(s) tramaron el imaginario de un trópico nevado, de una isla esteparia, de un "caribe soviético", para pensar la sovietización cultural. Diáspora(s) comienza por apropiarse de los autores del "deshielo" (como Kundera o Brodsky), pero sobre todo de la perspectiva que desde aquellas estepas permitían observar con lupa el conflicto de las pequeñas criaturas humanas en colisión con los grandes proyectos de la Modernidad.

Publicada en 2014, El imperio Oblómov de Carlos Aguilera persiste en aquellos problemas abiertos en la década del noventa. La dislocación temporal a partir del encuentro con un futuro pasado y la revisión de la categoría de lo humano mediante la infiltración de otras formas de organización corporal, insisten en preguntas todavía no resueltas, en el sentido de pensar qué significa una vida que produce y narra desde la isla.

\section{Obras citadas}

AAVV. 2013. "Nada como el afuera para ver lo enfermito que está el adentro. Entrevistas a Carlos A. Aguilera". La Habana Elegante. PrimaveraVerano de 2013. Número 53. http://www.habanaelegante.com/ Spring_Summer_2013/Entrevista.html.

Aguilera, Carlos. 1997. "Mao", Diáspora(s) No 1, septiembre de 1997, págs. 22-24.

. 2012 "Discurso de la madre muerta", en Discurso de la madre muerta. Tenerife, Baile del sol ediciones. . 2014 El imperio Oblómov. Sevilla, Espuela de Plata.

Bernabé, Mónica. 2012. "Las fronteras vacilantes del relato antillano. Para una teoría de la transculturación", en Graciela Salto (compiladora). Ínsulas y poéticas. Figuras literarias en el Caribe. Buenos Aires, Biblos, págs. 15-37.

Brodsky, Joseph. 1997. "Esa condición llamada exilio", Diáspora(s) No 1, septiembre de 1997, págs. 33-38.

Buck Morss, Susan. 2004. Mundo soñado y catástrofe. La desaparición de la utopía de masas en el Este y el Oeste. Madrid, A. Machado libros.

De la Nuez, Iván. 2001. "El Hombre Nuevo ante el otro futuro", De La Nuez, I. (comp.): Almanaque. Cuba y el día después. Barcelona, Mondadori, págs. 9-20.

Cabezas Miranda, Julio (compilador). 2013. Revista Diáspora(s). Edición Facsímil (1997-2002). Barcelona, Lingkua.

Casamayor-Cisneros, Odette. 2012. Utopía, distopía e ingravidez: reconfiguraciones cosmológicas en la narrativa pos-soviética cubana. Madrid, Iberoamericana-Veuvert.

Del Casal, Julián. 2012. "Un sacerdote ruso", en Flores de invernadero. Prosa y poesía (Schnirmajer, Ariela ed.). Buenos Aires, Corregidor, págs. 95-96.

Díaz, Duanel. 2007. "Muñequitos rusos, nostalgia cubiche". http://duaneldiaz. blogspot.com.ar/2007/04/muequitos-rusos-nostalgia-cubiche.html

Dorta, Walfrido. 2013 "Madrigueras de Carlos A., el 'checo'". La Habana elegante. Primavera-verano de 2013, núm. 53. http://www. habanaelegante.com/Spring_Summer_2013/InvitadoAguilera_Dorta.html\#nota 
Foucault, Michel. 2002. "Derecho de muerte y poder sobre la vida", en Historia de la sexualidad. 1. La voluntad de saber. Buenos Aires: Siglo XXI Editores, págs. 161-194.

Gilman, Claudia. 2012. Entre la pluma y el fusil. Debates y dilemas del escritor revolucionario en América Latina. Buenos Aires, Siglo XXI Editores.

Groys, Boris. 2008 Obra de arte total Stalin. Valencia, Pre-textos.

Le Breton, David. 2002. Antropología del cuerpo y modernidad. Buenos Aires, Nueva Visión.

Loss, Jacqueline. 2003. "Vintage Soviets in post-Cold War Cuba". Mandorla: Nueva Escritura de las Américas 7, págs. 79-84. 2009. "Despojos de lo soviético en Cuba. La estética del adiós". Otro lunes. Revista hispanoamericana de cultura. Año 3 No 8. http://otrolunes. com/archivos/08/html/este-lunes/este-lunes-n08-a11-p01-2009.html

Maccioni, Laura. 2013. "Retratos del Hombre Nuevo: figuras de la subjetividad en Pasajes de la guerra revolucionaria y "Comienza el desfile". Anclajes XVII.2 (diciembre 2013), págs. 33-45.

Marqués de Armas, Pedro. 2015. "Oblómov o la contra-ficción". Bazar americano. Mayo-junio 2015, AÑO XI, No 51. http://www.bazaramericano. com/resenas. php?cod $=510 \& p d f=s i$

Monteleone, Jorge. 1989. "Principio y futuridad en la vanguardia hispanoamericana". Cuadernos de Literatura, 4, Resistencia, Instituto de Letras, Facultad de Humanidades, Universidad Nacional del Nordeste, págs. 37-52.

Morejón Arnaiz, Idalia. 2012. "Diáspora(s): memoria de la posguerra". Crítica, v. 148, págs. 55-59.

. 2014. "Repertorio de poesía y performance. Cuba años noventa". Revista Badebec 7. http://www.badebec.org/badebec_7/sitio/pdf/ dossier_morejon_7.pdf

Ponte, Antonio José. 2007. La fiesta vigilada. Anagrama, Barcelona.

Puñales Alpízar, Damaris. 2013. Escrito en cirílico. El ideal soviético en la cultura cubana posnoventa. Santiago de Chile, Cuarto Propio.

Retamar, Roberto Fernández. 2004. Todo Calibán. Buenos Aires, Biblioteca virtual CLACSO.

Rojas, Rafael. 2009. El estante vacío. Literatura y política en Cuba. Barcelona, Anagrama.

Sánchez Mejías, Rolando. 1997. "Presentación", Revista Diáspora(s) No 1, pp. $1-4$.

Quintero Herencia, Juan Carlos. 2002. Fulguración del espacio. Letras e imaginario institucional de la Revolución Cubana (1960-1971). Rosario, Beatriz Viterbo. 